\title{
Pharmacological Types of Calcium Channels and Their Modulation by Baclofen in Cerebellar Granules
}

\author{
Carolina Amico, Carla Marchetti, Mario Nobile, and Cesare Usai \\ Istituto di Cibernetica e Biofisica, Consiglio Nazionale delle Ricerche, 16149 Genova, Italy
}

\begin{abstract}
Voltage-dependent calcium currents were measured by whole-cell recording technique in cultured cerebellar granule neurons from $8 \mathrm{~d}$ old rats, in $10 \mathrm{~mm} \mathrm{BaCl}$ and with a holding potential of $-80 \mathrm{mV}$. A saturating dose $(10 \mu \mathrm{M})$ of the dihydropyridine nimodipine reversibly inhibited the maximum current by $25 \%$ and the dose dependence showed IC ${ }_{50}$ close to $50 \mathrm{~nm}$. $\omega$-Conotoxin GVIA (cgtx, $5 \mu \mathrm{m}$ ) and $\omega$-agatoxin IVA (agatx, $200 \mathrm{~nm}$ ) irreversibly inhibited the current by $17 \%$ and by $47 \%$, respectively. The effect of nimodipine was additive with that of the toxins. The GABA ${ }_{B}$ agonist ( \pm )baclofen, or (-)baclofen $(100 \mu \mathrm{M})$, reduced the calcium current by $30 \pm 5 \%$, with a $\mathrm{IC}_{50} 4 \mu \mathrm{m}$. The effect was mediated by a pertussis toxin-sensitive G-protein. In cells treated with cgtx during the experiment or preincubated with the toxin for $30 \mathrm{~min}$, the effect of baclofen was significantly reduced. However, the action of baclofen was not confined to cgtx-sensitive channels: application of nimodipine or agatx resulted in a $50 \%$ reduction of the baclofen effect as well. In contrast, baclofen inhibited approximately the same amount of current both before and after the increase caused by the dihydropyridine agonist BayK 8644 and did not modify the slow BayK-induced tail current. These results indicate (1) the modulation through $\mathrm{GABA}_{\mathrm{B}}$ receptors does not clearly discriminate between pharmacologically distinct calcium channels and (2) L-type calcium channels represent an heterogeneous population in these neurons.
\end{abstract}

[Key words: dihydropyridines, $\omega$-conotoxin GVIA, $\omega$-agatoxin IVA, GABA $A_{\mathrm{B}}$ agonist, PTX-sensitive G-protein, calcium current]

Multiple types of pharmacologically distinct voltage-dependent calcium channels have been recognized in neurons (Fox et al., 1987; Aosaki and Kasai, 1989; Regan et al., 1991; Kasai and Neher, 1992). These channel types differ in the first place in their pharmacological sensitivity to specific ligands, which include dihydropyridines (DHPs) and several invertebrate toxins (McCleskey et al., 1987; Llinas et al., 1989; Hilliard et al., 1992; Mintz et al., 1992). Molecular cloning has revealed an even greater structural diversity of neuronal calcium channels and an increasing number of functional brain $\alpha_{1}$ subunits have been expressed and described (Snutch et al., 1991; Snutch and Reiner,

\footnotetext{
Received June 3, 1994; revised Oct. 13, 1994; accepted Oct. 18, 1994.

This work was partially supported by Bayer Italia S.p.a.

Correspondence should be addressed to Carla Marchetti, Istituto di Cibernetica e Biofisica. Consiglio Nazionale delle Ricerche, via De Marini 6, 16149 Genova, Italy.

Copyright (C) 1995 Society for Neuroscience 0270-6474/95/152839-10\$05.00/0
}

1992; Ellinor et al., 1993; Sather et al., 1993). Pharmacological and structural classification still waits for a clearer link to calcium channel physiological functions, such as synaptic transmission and control of neurotransmitter and hormone release. Recent works suggest that in mammalian central neurons and nerve terminals different types of calcium channels coexist (Turner et al., 1992; Takahashi and Momiyama, 1993) and may work in synergy to mediate a specific function (Turner et al., 1993).

In neurons, a most ubiquitous and widely studied effect is the G-protein mediated inhibition of calcium channels by a variety of neurotransmitters (Hille, 1992; Hescheler and Schultz, 1993). Since first reports in sensory neurons (Dunlap and Fishbach, 1981), this effect has been described and interpreted in many different ways (Bean, 1989; Pollo et al., 1992; Delcour and Tsien, 1993; Kuo and Bean, 1993), in view of its putative importance in presynaptic inhibition. In peripheral and clonal neurons, the inhibitory action of several neurotransmitters has been shown to affect mainly, if not exclusively, $\omega$-conotoxin (cgtx)sensitive channels (Kasai and Aosaki, 1989; Lipscombe et al., 1989; Caulfield et al., 1992; Elmslie et al., 1992; Cox and Dunlap, 1992; Kasai, 1992; Pollo et al., 1992), but in central neurons the picture appears more complex. For example, the $\mathrm{GABA}_{\mathrm{B}}$ agonist baclofen, which produces presynaptic inhibition in hippocampal slice preparations (Nicoll et al., 1990) and inhibits transmitter release in cerebellar granules (Huston et al., 1990), inhibits both cgtx- and DHP-sensitive calcium currents in hippocampal neurons (Scholz and Miller, 1991) and the P-type calcium current in other central neurons (Mintz and Bean, 1993).

In cerebellar granule cells, we and other authors have described a high-voltage-activated calcium current which is partially inhibited by baclofen (Wojcik et al., 1990; Marchetti et al., 1991). This current displays a complex pharmacological profile: it is increased by the DHP agonist BayK 8644, but is only partially sensitive to antagonist DHPs and cgtx. Therefore we have addressed the question of whether these different pharmacological types of channels also perform different functions, for instance they possess different sensitivity to modulation. We have used the $\mathrm{GABA}_{\mathrm{B}}$ agonist induced modulation as a model of a physiological response and present here a more detailed investigation of the pharmacological components of this current and their selective inhibition by baclofen.

\section{Materials and Methods}

Cell culture. Cerebellar granule cells were prepared from $8 \mathrm{~d}$ old rats following the procedure of Levi et al. (1984), as previously described (Marchetti et al., 1991). Neurons were maintained in Basal Eagle's culture medium, supplemented with $10 \%$ fetal calf serum and $100 \mu \mathrm{g} / \mathrm{ml}$ gentamicin. The concentration of $\mathrm{KCl}$ was elevated to $25 \mathrm{mM}$ to assure longer survival of granule cells (D'Mello et al., 1993). Cultures were treated with $10 \mu \mathrm{M}$ cytosine arabinoside from day 1. Experiments were 
Figure 1. Effect of dihydropyridines on granule cell calcium current. $A, \mathrm{Cur}$ rent traces evoked by depolarizing steps to $+10 \mathrm{mV}$ from a holding potential of $-80 \mathrm{mV}$ in control solution $\left(10 \mathrm{mM} \mathrm{BaCl}_{2}\right)$, in the presence of 10 $\mu \mathrm{M}$ nimodipine and after wash. $B$, Time course of the effect of two different doses of nimodipine. $C$, Dose dependence of the effect of nimodipine. Each cell was treated with one or two doses of nimodipine. Points represent mean \pm SEM, and the number of cells tested is indicated in brackets. The solid line is drawn according to the best fit with an occupancy model with a single binding site,

$$
Y=\text { Effect }_{\text {max }} /\left(1+\mathrm{IC}_{50} / X\right)
$$

where $Y=100 \times\left(I-I_{\text {(nimo) }}\right) / I, I$ is the current before application of nimodipine, $I_{\text {(nima) }}$ is the current in the presence of nimodipine, and $X$ is the concentration of nimodipine. The best fit gave $\mathrm{IC}_{50}=56 \mathrm{nM}$ and Effect $\mathrm{t}_{\max }=25 \% . D$, Dose dependence of the effect of BayK 8644. Each cell was treated with one to three doses of the agonist. Points represent mean $\pm S E M$, and the number of cells tested is indicated in brackets. The solid line is the best fit according to the function

$$
\begin{aligned}
Y= & \mathrm{Effect}_{\text {max } 1} /\left(1+\mathrm{EC}_{50(1)} / X\right) \\
& +\mathrm{Effect}_{\max 2} /\left(1+\mathrm{EC}_{50(2)} / X\right),
\end{aligned}
$$

where $Y=100 \times\left(I_{(\mathrm{BayK})}-I\right) / I, I$ is the current before application of BayK, $I_{(\mathrm{BayK})}$ is the maximum amplitude of the current in the presence of BayK, and $X$ is the concentration of BayK. The best fit gave the following values of the four parameters: Effect $t_{\max 1}=40 \%, \mathrm{EC}_{50(1)}=$ $0.87 \mathrm{nM}$, Effect $_{\max 2}=130 \%, \mathrm{EC}_{50(2)}=$ $323 \mathrm{nM}$.
A

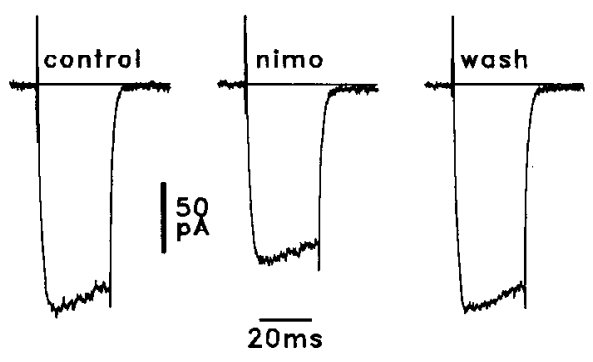

C

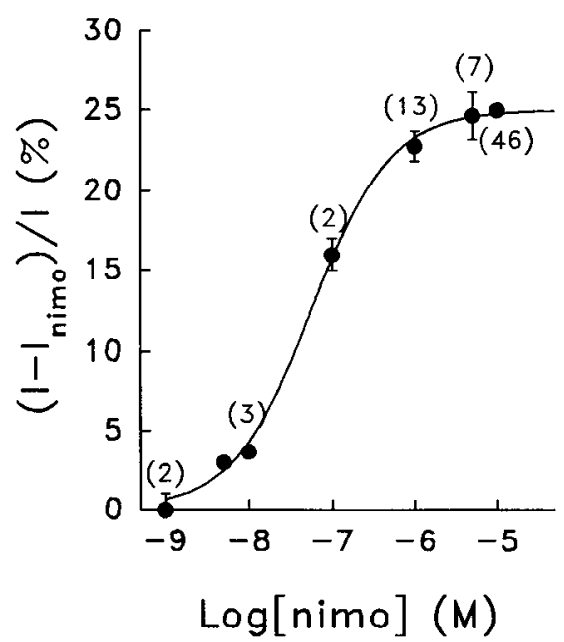

B

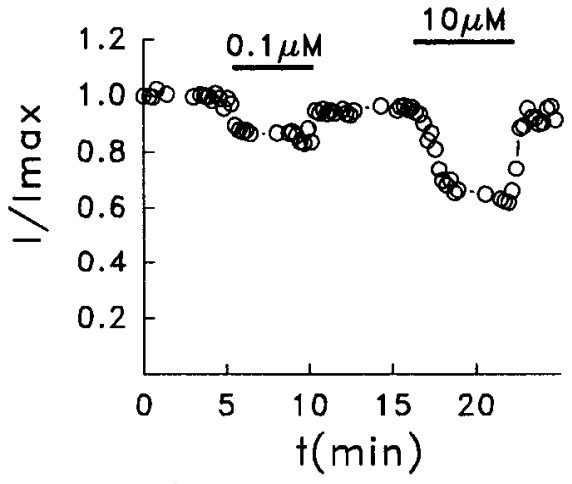

D

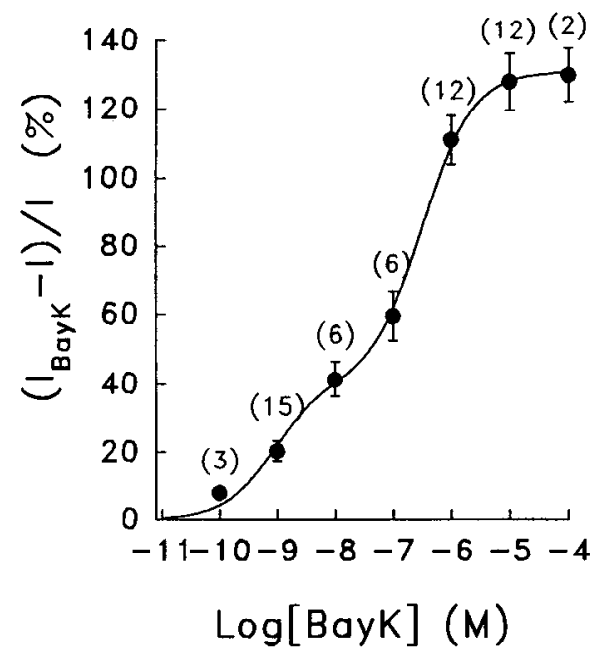

carried out in cultures between days 5 and 13 in vitro (5-13 DIV). Up to $95 \%$ of the cells were identified as granule cells, as confirmed by the following observations: (1) all neurons have similar morphology; (2) the properties of voltage-dependent calcium currents are reproducible; (3) all the cells respond to application of $\gamma$-aminobutyric acid (GABA) with the activation of a chloride current (Marchetti et al., 1991 ); and (4) there is very little GABA production during time in culture.

Electrophysiology. Membrane currents were measured in whole-cell clamp configuration by a patch-clamp L/M EPC7 amplifier (List Electronic, Darmstadt, Germany), as in our previous study (Marchetti et al., 1991). Electrodes were manufactured from borosilicate glass capillaries (Hilgenberg $\mathrm{GmbH}$, Malsfeld, Germany) and had resistance of $\approx 5 \mathrm{M} \Omega$ Voltage stimulation and data acquisition were performed by a 80486 PC through a 16 bit Digidata 1200 interface (Axon Instrument Inc., Foster City, CA). Currents were sampled at a frequency of $80 \mu \mathrm{sec}$ per point. Capacitance transients were minimized by analog compensation. Unless otherwise stated, all currents traces were corrected for leak and residual capacitance transients by a computer generated $\mathrm{P} / 4$ protocol. The holding potential was set to $-80 \mathrm{mV}$ in all the experiments reported, but less negative holding potentials were also tested. Holding the membrane at $-60 \mathrm{mV}$ or less always resulted in a considerable loss of current (up to $50 \%$ at $-40 \mathrm{mV}$ ); the current decreased with a slow time course and took several minutes to reach the new steady-state value. Frequently, this "very slow inactivation" was irreversible. Thus, a holding potential of $-80 \mathrm{mV}$ appeared the most suitable condition to record the total calcium current. Moreover, we do not have indications that a less negative holding potential (up to $-40 \mathrm{mV}$ ) significantly favored antagonist DHP binding (Marchetti et al., unpublished observations).

Current traces were analyzed with pCLAMP (Axon Instruments Inc.) and SIGMA PLot (Jandel Scientific, Erkrath, Germany) software. The current traces shown in the figures are averages over 3-12 consecutive sweeps. The current values were obtained averaging at least 20 points at the peak level. Data are given as mean $\pm \mathrm{SD}$, with the exception of the dose-dependence curves (Fig. $1 C, D$; see Fig. $5 C$ ) were data points represent mean $\pm S E M$. Statistical significance of the difference between the data $(p)$ was evaluated with the Student's $t$ test.

Solutions. The external solution contained (in $\mathrm{mM}$ ) tetraethylammonium chloride (TEACl) $130, \mathrm{BaCl}_{2} 10, \mathrm{MgCl}_{2}$ 1, 4-aminopyridine (4AP) 4 , glucose 10 , HEPES $10(\mathrm{pH}=7.4)$. The internal (pipette) solution contained (in $\mathrm{mm}$ ) $\mathrm{CsCl} 20, \mathrm{CsOH} 110$, aspartic acid $100, \mathrm{MgCl}_{2}$ 4, EGTA 5, HEPES 5, ATP 3, and GTP 0.1. pH adjusted at 7.4 with Trizma base. In some experiments, GTP was omitted.

The standard physiological saline used in incubation of the toxins contained (in mM) $\mathrm{NaCl} \mathrm{135,} \mathrm{KCl} 5.4, \mathrm{CaCl}_{2} 1.8, \mathrm{MgCl}_{2}$ 1, HEPES 5; $\mathrm{pH}=7.4$ with $\mathrm{NaOH}$.

The bath solution was exchanged by gravity ( $\approx 3 \mathrm{ml} / \mathrm{min}$ flow). All tubing were treated by Sigmacote (Sigma Chemical Co., St. Louis, MO) to minimize contamination of containers. Dihydropyridines were made up in $100 \%$ ethanol at a concentration of $10 \mathrm{mM}$ and adequately protected from light. Control experiments were performed to verify that the solvent was completely ineffective at this dilution. Toxins were diluted in the bath solution and pipetted directly to the recording chamber in appropriate volumetric amounts to obtain the desired concentration. Nimodipine was usually applied through the perfusion system; however, 
The Journal of Neuroscience, April 1995, 15(4) 2841

A

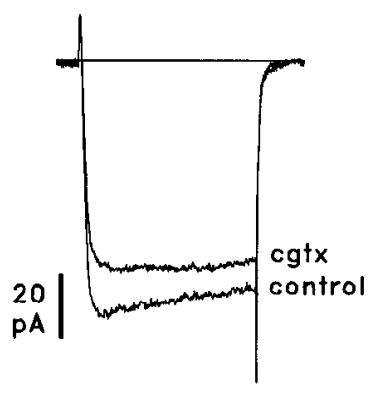

$\overline{20 m s}$

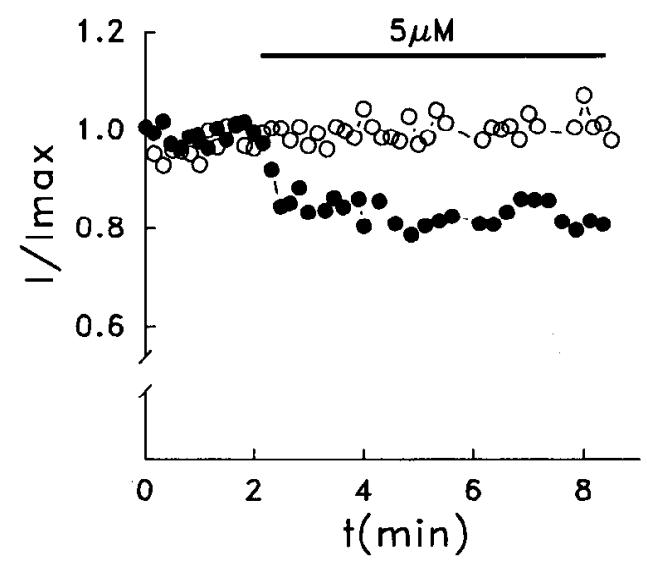

B

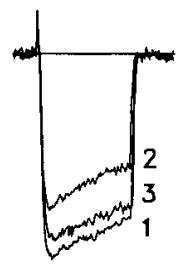

$\mid \begin{aligned} & 40 \\ & \mathrm{PA}\end{aligned}$
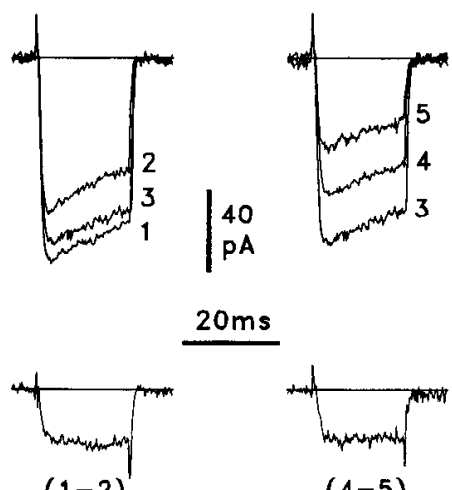

$20 \mathrm{~ms}$

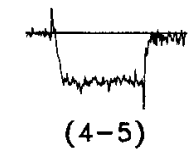

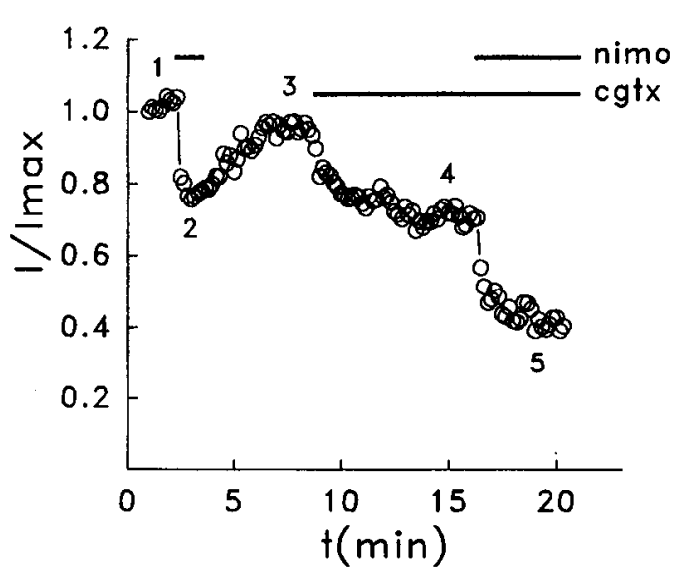

Figure 2. Effect of cgtx in acute and chronical treatment. A:Left, Current traces $(+10 \mathrm{mV}$, from $-80 \mathrm{mV})$ in control and after application of $5 \mu \mathrm{M}$ cgtx in the external bath (acute treatment). Right, Time-course of the effect on a control cell (solid circles) and lack of effect on a cell incubated with $5 \mu \mathrm{M}$ cgtx for $30 \mathrm{~min}$ in standard saline before starting the experiment (chronical treatment, open circle). $B$, Effect of 10 $\mu \mathrm{M}$ nimodipine before and after application of $5 \mu \mathrm{M}$ cgtx: representative traces (left) and time course (right). Traces 1 (control), 2 (nimodipine), 3 (recovery) refer to the first application of nimodipine in the absence of cgtx; the corresponding difference trace $(I-$ 2 , nimodipine-sensitive current) is shown below; trace 4 is the current recorded in the presence of cgtx, and trace 5 the current in the presence of both cgtx and nimodipine; the difference trace (4-5) is shown below and represents the nimodipine-sensitive current in the presence of cgtx. The current blocked by nimodipine is approximately the same before and after the cgtx treatment. when toxins were already present in the bath and the flow was stopped, subsequent addition of nimodipine was accomplished by pipetting it to the chamber; in this latter case, the effect of the drug was sometime slower (see Fig. 3C). Nevertheless, we verified that the percentage of current blocked was the same with both modes of application.

In some experiments, culture were treated with pertussis toxin $(200$ or $400 \mathrm{ng} / \mathrm{ml}$, Sigma Chemical Co.) in the culture medium for 12-16 hr.

Chemicals. $\omega$-Conotoxin GVIA was obtained from Bachem (Bubendorf, Switzerland) and $\omega$-agatoxin IVA from Peptides International (Louisville, KY) and Latoxan (Rosans, France). Nimodipine and BayK 8644 were provided by Bayer Italia S.p.a (Milano, Italy). All other chemicals were purchased from Sigma Chemical Co.

\section{Results}

Currents were recorded in a $10 \mathrm{~mm}$ Ba external solution, but will be referred to as "calcium current," as in previous work (Marchetti et al., 1991). This current was identified as a highvoltage-activated calcium current on the basis of the following properties: it activated between -40 and $-30 \mathrm{mV}$ and attained a maximum amplitude at +10 or $+20 \mathrm{mV}$; it was reduced to approximately $50 \%$ when barium was equimolar substituted with

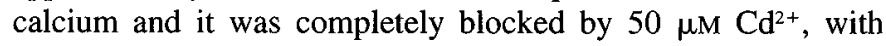
$\mathrm{IC}_{50}=1.22 \mu \mathrm{M}$.

\section{Effect of dihydropyridines}

A saturating dose $(10 \mu \mathrm{M})$ of the DHP antagonist nimodipine inhibited the calcium current by $25 \pm 3 \%$ (mean $\pm \mathrm{SD}, n=$ 46) (Fig. $1 A, B$ ). The dose dependence of nimodipine inhibition showed an $\mathrm{IC}_{50}$ close to $50 \mathrm{nM}$ (Fig. $1 C$ ). The effect of nimodipine was completely reversible following wash, but the recov- ery was strictly dependent on the duration of treatment. An almost complete $(90 \%)$ recovery was achieved in 30 out of 46 cells after $10 \mu \mathrm{M}$ nimodipinc. Similar results were obtained with the DHP nifedipine.

The agonist DHP BayK 8644 caused an increase of the current, which was much more pronounced at low membrane potential. In the presence of $1 \mu \mathrm{M} \mathrm{BayK}$, the current at $-10 \mathrm{mV}$ increased by up to $300 \%$ of control value, while the current at $+10 \mathrm{mV}$ increased by $130 \pm 50 \%$ (mean $\pm \mathrm{SD}, n=12$ ). This effect resulted in a shift of the potential value at which the current is half activated (Marchetti et al., 1991). To determine the dose-dependence curve, the increase was evaluated at a membrane potential of $+10 \mathrm{mV}$, for consistency with other conditions. The dose dependence of BayK effect extended over $5 \mathrm{Log}$ units and could not be approximated by an occupancy model with a single binding site. Instead, as previously proposed (Brown et al., 1986), a double-site model could adequately fit the results. The two independent sites postulated by this model showed $\mathrm{IC}_{50}$ of $1 \mathrm{nM}$ and $300 \mathrm{nM}$ respectively (Fig. 1D).

\section{Effect of $\omega$-conotoxin GVIA}

Cgtx, fraction GVIA ( $5 \mu \mathrm{M})$, inhibited the total calcium current by $17 \pm 2 \%$ (mean $\pm \mathrm{SD}, n=14$ ) (Fig. $2 A$ ). The effect of this dose of toxin was complete in $<1 \mathrm{~min}$ and was irreversible, despite prolonged wash. In other experiments, cells were pretreated with $5 \mu \mathrm{M}$ cgtx for $30 \mathrm{~min}$ in standard physiological saline; in these cells, further acute application of cgtx to the bathing solution did not produce any reduction of the current, 
A

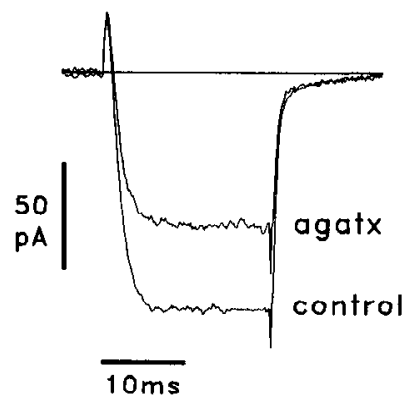

Efgure 3. Effect of agatx. $A$, Curren traces $(+10 \mathrm{mV}$, from $-80 \mathrm{mV})$ in control and after application of $200 \mathrm{nM}$ agatx. $B$, Time-course of the effect of 100 and $200 \mathrm{~nm}$ agatx in two different cells. $C$, Effect of $10 \mu \mathrm{M}$ nimodipine before and after $200 \mathrm{nM}$ agatx treatment: representative traces (left) and time course (right). Traces $1-3$ refer to the first application of nimodipine in the absence of agatx; the corresponding difference trace $(1-2$, nimodipine-sensitive current) is shown below; trace 4 is the current recorded in the presence of agatx, trace 5 is the current in the presence of both agatx and nimodipine, and trace 6 is the current following wash out; the nimodipine-induced depression was reversible, while the agatx effect was not. The difference trace (45 ) is shown below and represents the nimodipine-sensitive current in the presence of agatx: this current is approximately the same as in control (no toxin) condition.

C
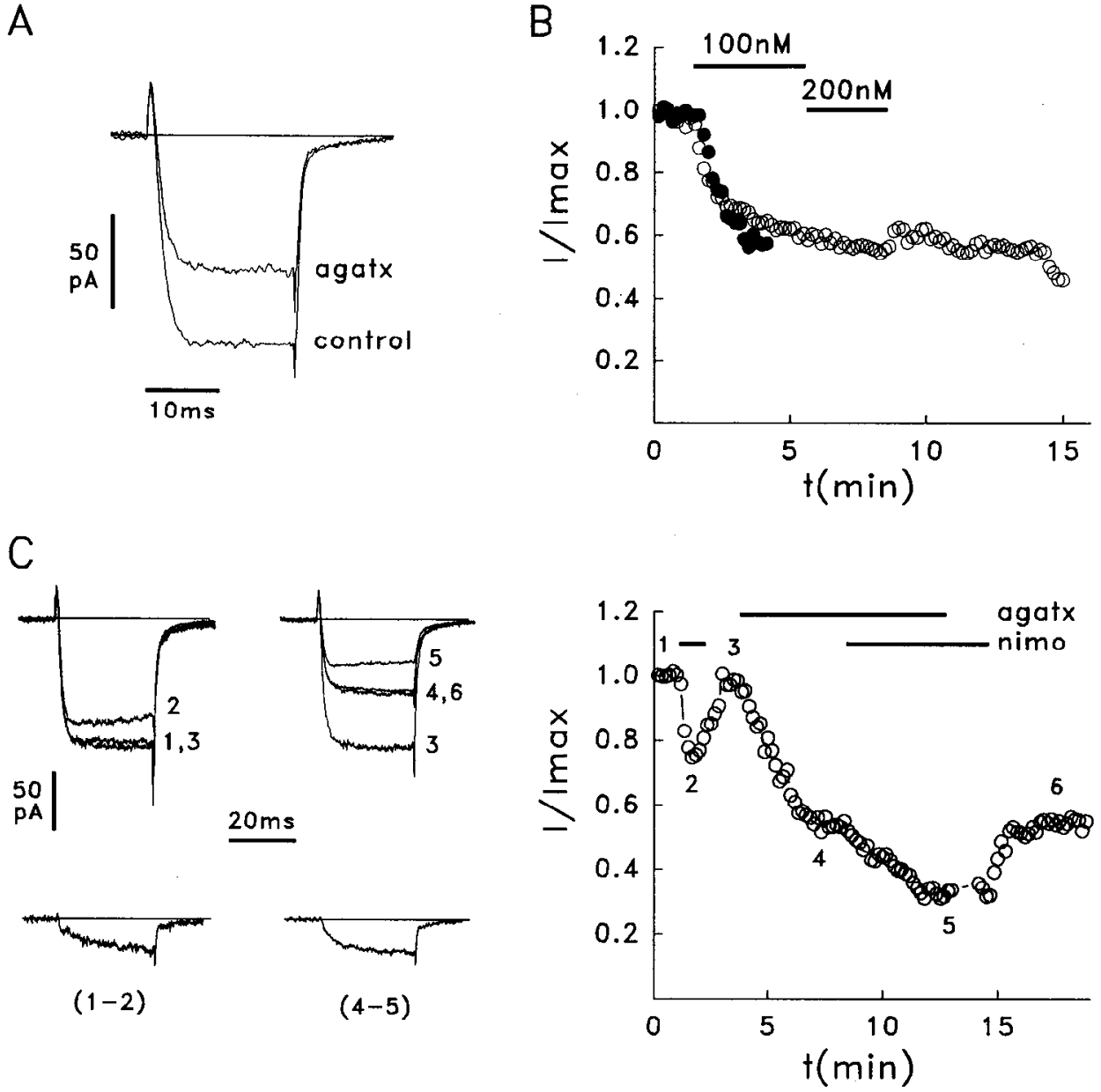

indicating that all sites were occupied and irreversibly bound by the toxin.

The effects of the nimodipine and cgtx were approximately additive: the reduction caused by cgtx was independent of the presence of DHP and the average combined effect was $43 \pm$ $5 \%$ (mean $\pm \mathrm{SD}, n=8$ ) (Fig. $2 B$ ). In cells chronically treated with $5 \mu \mathrm{M}$ cgtx for $30 \mathrm{~min}$, nimodipine inhibited $32 \pm 11 \%$ (mean $\pm \mathrm{SD}, n=6$ ) of the residual current.

\section{Effect of $\omega$-agatoxin IVA}

Bath application of either 100 or 200 nM $\omega$-agatoxin IVA (agatx) depressed the calcium current by $47 \pm 6 \%$ (mean $\pm \mathrm{SD}, n=$ 22) and these doses can be taken as saturating (Fig. $3 A, B$ ). A dose of $50 \mathrm{nM}$ agatx depressed the current by $21 \pm 7 \%$ (mean $\pm \mathrm{SD}, n=4$ ), while lower doses failed to produce any detectable effect. The effect of the higher doses developed with time constant $\left(\tau_{\text {on }}\right)$ of $40 \pm 11 \mathrm{sec}(n=7)$. Recovery was not observed despite prolonged wash, and, different from P-type calcium channels in cerebellar Purkinje neurons (Mintz et al., 1992), depolarizing prepulses to very positive potential (up to $100 \mathrm{mV}$ ) failed to determine any release of the block.

The effect of agatx was additive, at a good approximation, with that of nimodipine, as indicated by the fact that nimodipine blocked the same amount of current both before and after agatx application (Fig. 3C). A similar result was obtained in six cells. Therefore, different from recent results in other preparations (Brown et al., 1994), our data suggest that a dose of $10 \mu \mathrm{M}$ nimodipine exerts its effect on a channel type distinct from that blocked by agatx.

The effects of cgtx and agatx showed partial additivity (Fig. 4). With respect to the control current (the current before any treatment), the combined effect of the two toxins reduced the current by $56 \pm 6 \%$ (mean $\pm \mathrm{SD}, n=5$ ).

In the presence of the three antagonists, a resistant current was present and was in the range of $20-30 \%$ of the total current. This residual current was not investigated further, but did not show major differences in activation and inactivation kinetics from the other components and it was completely suppressed in the presence of $50 \mu \mathrm{M} \mathrm{Cd}^{2+}$.

\section{Effect of baclofen}

Application of ( \pm )baclofen caused a fast, quickly reversible, but largely incomplete reduction of the calcium current, which was accompanied by a moderate kinetic slowing (Fig. 5). Baclofen did not affect the baseline current and the resting conductance in these conditions, as shown in the raw records of Figure 5A. The dose dependence of the effect of baclofen showed an $\mathrm{IC}_{50}$ equal to $4 \mu \mathrm{M}$ and a saturating dose $(100 \mu \mathrm{M})$ inhibited $35 \pm$ $9 \mathrm{pA}$ of the current $(30 \pm 5 \%$, mean $\pm \mathrm{SD}, n=36)$ (Fig. $5 C$ ). Quantitatively similar results were obtained with (-)baclofen: in six cells, $100 \mu \mathrm{M}$ of the racemic compound inhibited the current by $29 \pm 2 \%$, and the same dose of $(-)$ baclofen inhibited the current by $28 \pm 2 \%$ (mean $\pm \mathrm{SD}$ ). When GTP was not present in the recording pipette, baclofen was completely inef- 
A

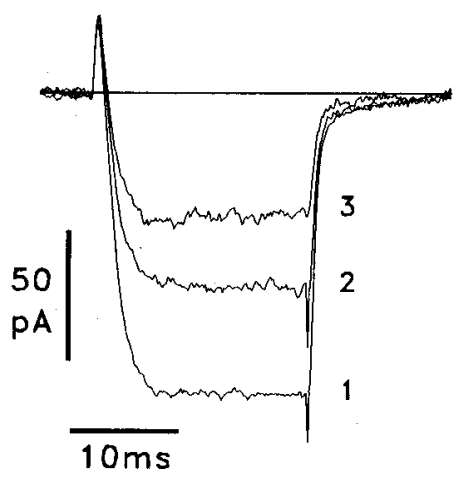

B

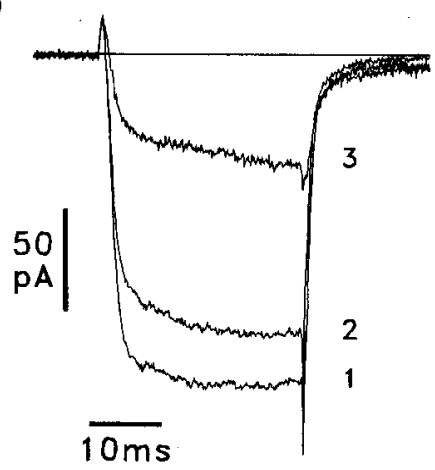

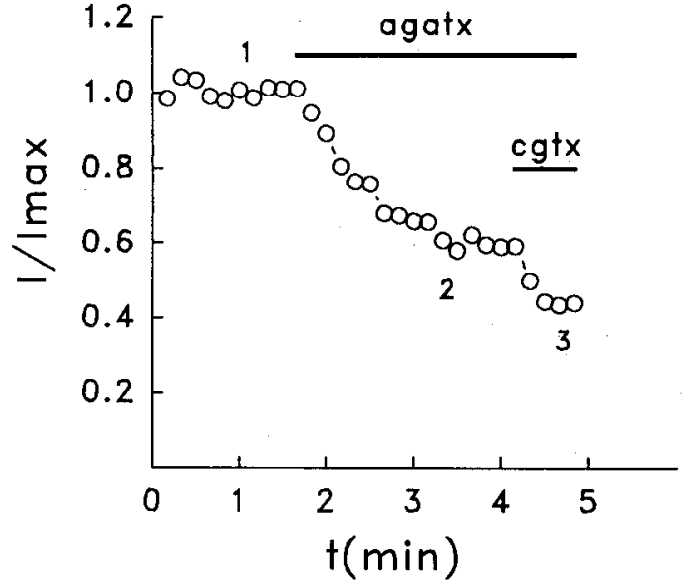

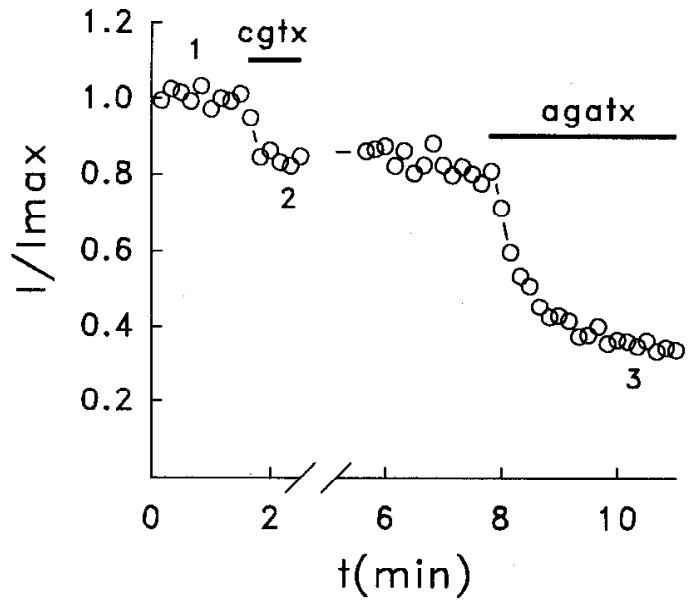

Figure 4. Combined effects of the two toxins. $A$, Effect of $5 \mu \mathrm{M}$ cgtx in the presence of $200 \mathrm{~nm}$ agatx. Representative traces $(+10 \mathrm{mV}$, from -80 $\mathrm{mV}$ ) (lett) and time course (right). $B$, Effect of $200 \mathrm{nM}$ agatx in the presence of $5 \mu \mathrm{M}$ cgtx. Representative traces (left) and time course (right). fective $(n=3)$. Also, after incubation with pertussis toxin (PTX), the effect of baclofen was almost totally prevented ( $n=$ 8) (Fig. 5D). These observations indicate that baclofen modulates the calcium current through a PTX-sensitive G-protein.

\section{Combined effects of baclofen and the blockers}

In the presence of cgtx (acute treatment with $5 \mu \mathrm{M}$ ), the cffect of baclofen was significantly reduced: in eight cells, the current inhibited by baclofen was $39 \pm 8 \mathrm{pA}$ in control and $19 \pm 5$ pA $(15 \pm 3 \%$ of the initial current) in the presence of $\operatorname{cgtx}(p$ $<0.01)$. Cgtx had hardly any effect in the presence of baclofen: in six cells, after addition of baclofen to the bath, cgtx blocked $5 \pm 4 \mathrm{pA}$ of the current ( $3 \pm 2 \%$ of the initial current) with $p$ $<0.01$ with respect to the average control inhibition caused by this toxin (22 \pm 8 pA, $n=15$ ) (Fig. $6 A, B)$.

However, the cgtx-sensitive current was always smaller than the baclofen-inhibited fraction of the current and this indicated that the effect of baclofen was not confined to cgtx-sensitive channels. Also, in cells pretreated with $5 \mu \mathrm{M}$ cgtx for $30 \mathrm{~min}$ (chronic treatment), a significant inhibition $(17 \pm 7 \mathrm{pA}$ equal to $15 \pm 4 \%$ of the residual cgtx-resistant current, $n=11$ ) was still observed (Fig. 6D).

The cgtx-insensitive, baclofen-sensitive current revealed a complex composition, because it appeared to be blocked by both agatx and nimodipine. The actions of nimodipine and baclofen were not additive, but there was a significant overlap: the combined application of nimodipine and baclofen was more effective than nimodipine or baclofen alone, but less effective than the sum of the effects of the two drugs when applied separately (Fig. $6 C$ ). In 11 cells, the current inhibited by baclofen was $36 \pm 8$ $\mathrm{pA}$ in control and $19 \pm 7 \mathrm{pA}$ in the presence of $1-10 \mu \mathrm{M}$ nimodipine $(p<0.01)$. In addition, in cells pretreated with cgtx and in the presence of nimodipine, the effect of baclofen was complctely suppressed (Fig. 6D).

The current inhibited by baclofen was also significantly reduced in the presence of agatx (Fig. $7 A, B$ ): in nine cells, baclofen suppressed $30 \pm 7 \mathrm{pA}$ of the current in control and $13 \pm$ $1 \mathrm{pA}$ in the presence of agatoxin $(p<0.01)$. In three cells preincubated with $200 \mathrm{nM}$ agatx for $30 \mathrm{~min}$, baclofen inhibited $16 \pm 6 \mathrm{pA}(p<0.01$ with respect to the average control inhibition; Fig. $7 C$ ).

All the results are summarized in Figure $7 D$.

\section{Combined effects of baclofen and BayK}

In contrast with nimodipine, baclofen did not affect the BayKmodified calcium current. This is shown by the following observations: baclofen inhibited the same amount of current both before and after the enhancement caused by BayK (Fig. $8 A, B$ ) and baclofen did not affect the slow BayK-induced tail current (Fig. 8C). A similar result was obtained when the DHP agonist was applied in the presence of baclofen (Fig. $8 D$ ): the current increased to a value lightly smaller than that reached with BayK applied in control condition, due to the block of BayK-insensitive channels, but the slow tail current displayed a comparable 
Figure 5. Effect of baclofen on the granule cell calcium current. $A$, Traces of the current in control and in the presence of $100 \mu \mathrm{M}$ baclofen. Responses to voltage steps from -80 to $+10 \mathrm{mV}$, uncorrected for leak and capacitance transients (left); responses to voltage steps from $-80 \mathrm{mV}$ to $-50 \mathrm{mV}$, showing the absence of any effect on the baseline current and resting conductance (middle). Corrected traces $(+10$ $\mathrm{mV}$, from $-80 \mathrm{mV}$ ) (right). The current recovered fully during wash, but the corresponding traces are not shown for clarity. $B$, Current-voltage relationship from a different cell in control (open circles) and in the presence of $100 \mu \mathrm{M}$ baclofen (solid circles). $C$, Dose dependence of the baclofen effect. Points are averages over the number of experiments indicated in brackets; error bars represent SEM. The solid line is drawn according to an occupancy model with a single binding site, as in Figure $1 C$, with $Y=100 \times$ $\left(I-I_{\text {(baclo) }}\right) / I . I$ is the current beforc application of baclofen, $I_{(\text {baclo })}$ is the current in the presence of baclofen and $X$ is the concentration of baclofen. The best fit gave IC50 $=3.9 \mu \mathrm{M}$ and $\mathrm{Ef}$ fect $_{\max }=30 \%$. $D$, From left to right, time course of the effect of $100 \mu \mathrm{M}$ baclofen in control conditions (GTP in the pipette, no treatment), in the absence of GTP in the pipette and after pretreatment with PTX (12-16 hr).
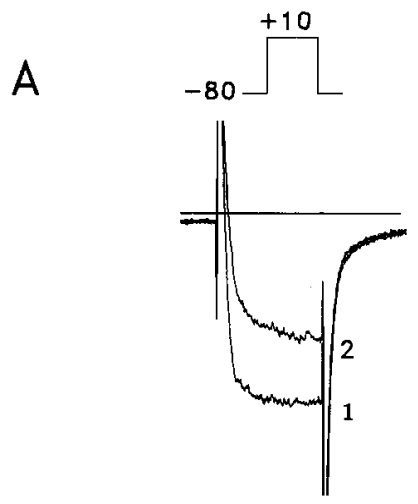

$B$
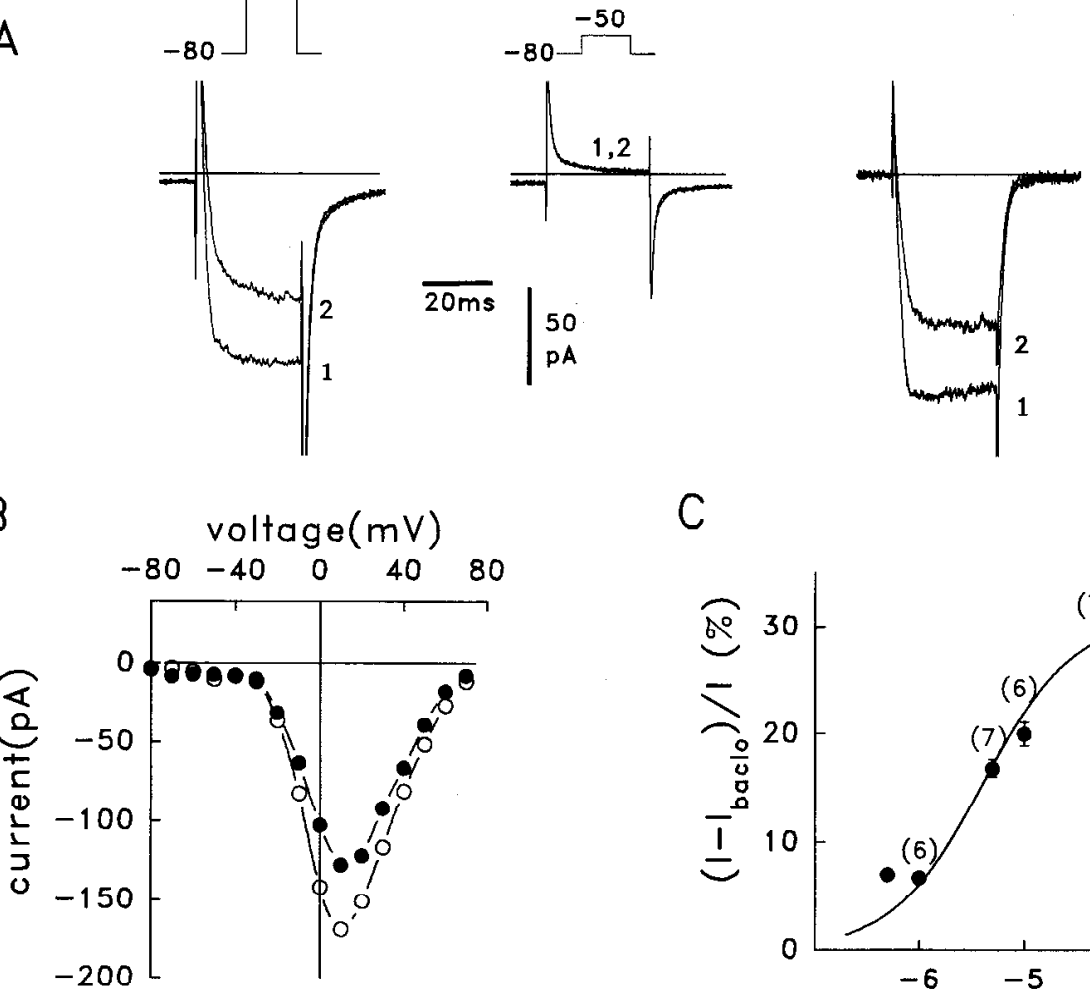

1 control

2 baclo

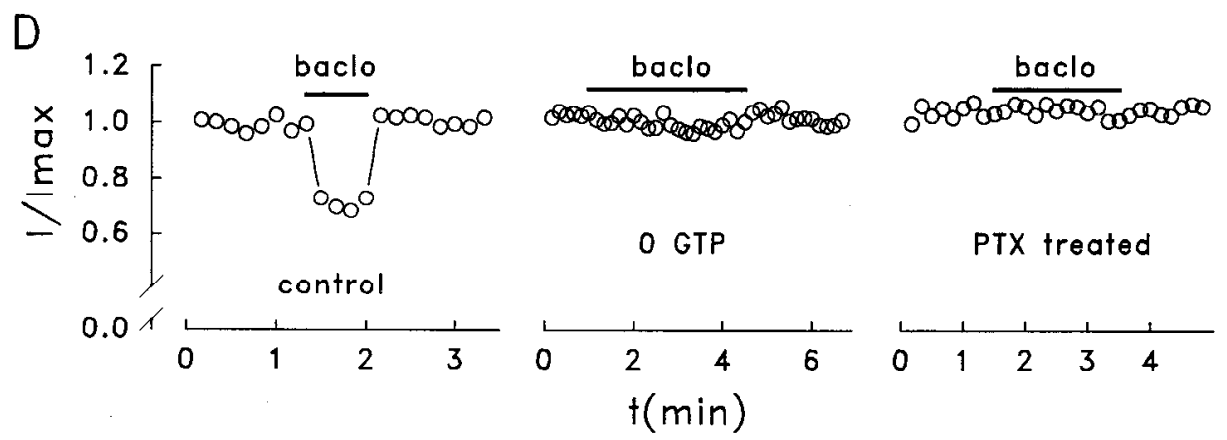

amplitude. This result was confirmed in 10 cells. This was also true at lower doses of the agonist (10 $\mathrm{nM})$, that is, in the range of high affinity constant $(n=10)$.

\section{Discussion}

The calcium current of cerebellar granule cells is maximally inhibited by nimodipine by $25 \%$, by cgtx by $17 \%$, and by agatx by $47 \%$. These percentages represent the average values obtained in a significant number of trials on more than 200 cells in the same culture conditions. No correlation with the age of the culture was detected during the period of investigation (5 13 day in vitro, DIV). The first question addressed by the present work is whether these pharmacological agents block calcium channels selectively or they target mixed populations of channels. The existence of mixed populations has been postulated frequently and, in particular, it has been suggested that a high dose of antagonist DHPs might block different types of calcium channels (Plummer et al., 1989; Regan et al., 1991; Brown et al., 1994). The dose dependence of nimodipine action presented in Figure $1 C$ contrasts with this possibility because the inhibition caused by the maximum dose tested $(10 \mu \mathrm{M})$ was not signifi- cantly different from that caused by $1 \mu \mathrm{M}$. Moreover, the effect of nimodipine was additive with both that of cgtx and agatx.

On the other hand, recent structural analysis suggests that the three classes here identified as cgtx-, DHP-, and agatx-sensitive channels do not represent homogeneous population of channels, but constitute "families" or "super families" with significant pharmacological and functional diversities (Snutch et al., 1990; Snutch and Reiner, 1992). In particular, the existence of at least two types of DHP-sensitive neuronal calcium channels, as well as isoforms generated by alternative splicing (Snutch and Reiner, 1992), together with increasing evidences of multiple DHP-binding sites (Brown et al., 1986; Tang et al., 1993) and both functional (Forti and Pietrobon, 1993) and pharmacological diversity (Plummer et al., 1989; Regan et al., 1991; Brown et al., 1994) furnish a picture of significant variation within the DHP-sensitive channel class. This might explain the differences in the interaction of nimodipine and BayK with calcium channels reported here. For example, in contrast with the results obtained with BayK (Fig. 1D), it was not possible to resolve a clear inflexion in the dose-response curve of nimodipine either from 
A
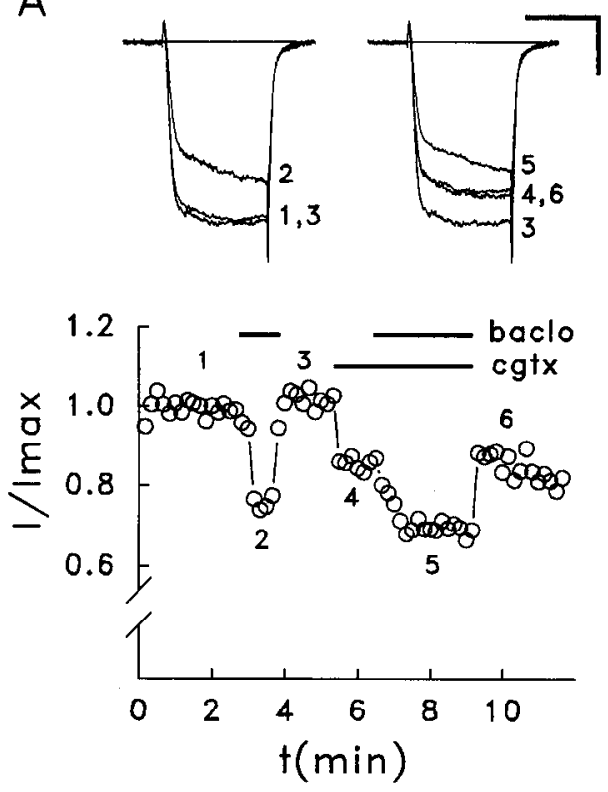

C
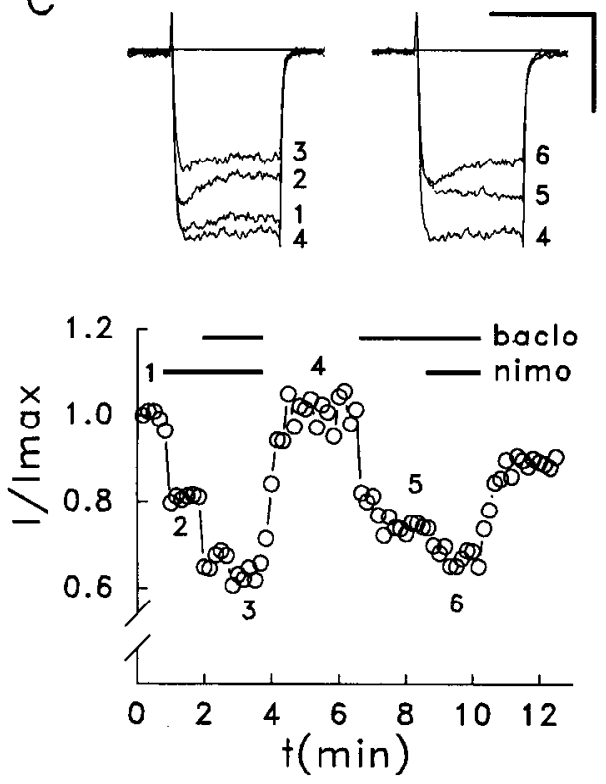

B
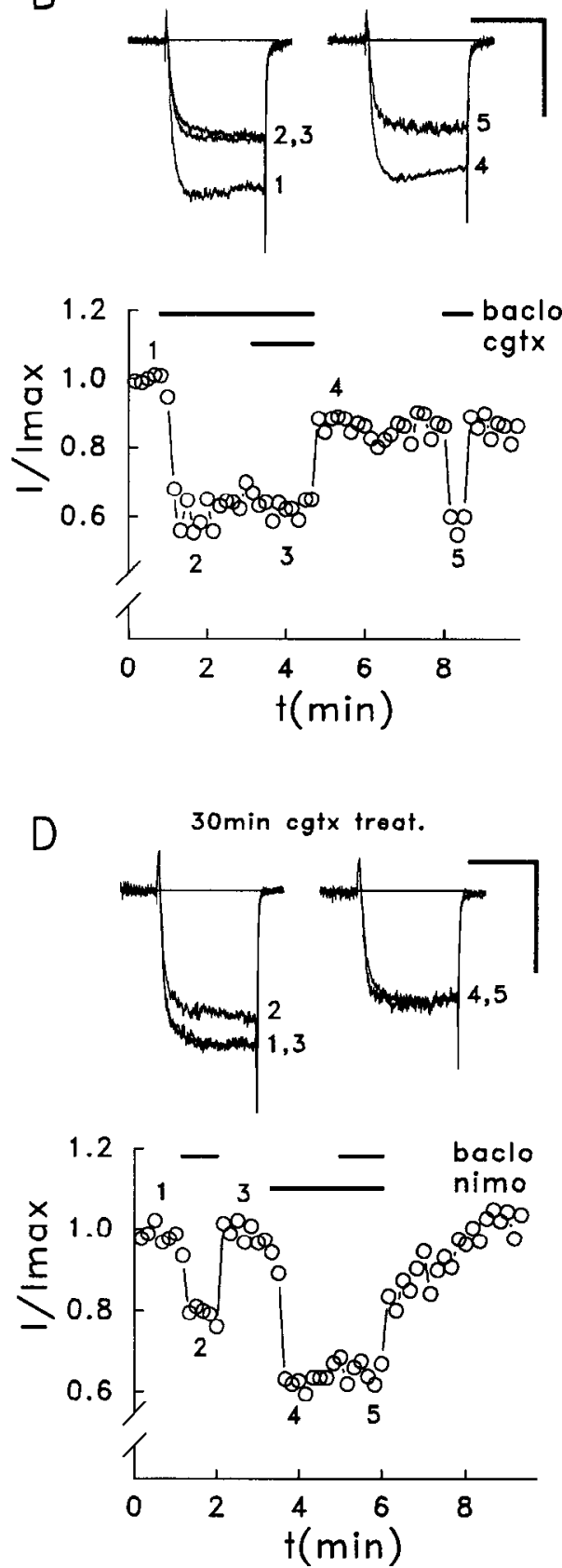

Figure 6. Combined effect of baclofen, cgtx, and nimodipine. In each case, representative traces of the current at $+10 \mathrm{mV}$ are shown above the corresponding time course of the experiment. Numbers indicate in which conditions the traces were recorded. The concentration of baclofen was $100 \mu \mathrm{M}$. $\Lambda$, Effect of baclofen before and after application of cgtx. $B$, Effect of cgtx in the presence of baclofen. $C$, Effect of $10 \mu \mathrm{m}$ nimodipine before and after application of baclofen. $D$, Effect of baclofen before and after application of nimodipine in a cell pretreated with 5 $\mu \mathrm{M}$ cgtx in standard saline for $30 \mathrm{~min}$. Calibration: 50 pA, $20 \mathrm{msec}$
$-80 \mathrm{mV}$ (Fig. $1 C$ ) or $-50 \mathrm{mV}$ (Marchetti et al., unpublished observations).

A similar discussion applies to agatx-sensitive channels. In cerebellar granule cells, agatx-sensitive channels differ in many respects from the P-type channels described in cerebellar Purkinje cells (Llinas et al., 1989; Mintz et al., 1992; Usowicz et al., 1992). First, at low $(<50 \mathrm{nM})$ concentrations, agatx was virtually ineffective on these currents, at least in the timc coursc of a typical experiment. Second, the block by higher doses could not be reversed by depolarizing pulses, a property which has been well documented for P-type channels (Mintz et al., 1992). Therefore these channels may be a different subtype belonging to the "non-L" super family, possibly similar to the recently proposed Q-type channels (Zhang et al., 1993; Randall et al., 1993; Soc Neurosci Abstr 19:1478). Finally, the action of the agatx was apparently additive with that of cgtx (Fig. 4), but from the average value of the combined inhibition a partial overlap cannot be ruled out completely.

The second main question addressed by this work is whether the modulatory effect of baclofen is confined to a pharmacologically identified class of channel.

The action of baclofen is mediated by a PTX-sensitive G-protein, in agreement with previous observations in sensory (Dolphin and Scott, 1987) and central neurons (Sah, 1990; Mintz and Bean, 1993), including cerebellar granule cells (Huston et al., 1993). Similar to other neurotransmitters (Marchetti et al., 1986; Dolphin and Scott, 1987; Kasai and Aosaki, 1989; Elmslie et al., 1990), baclofen also affected the current kinetics, but a voltage dependence of the effect (Bean, 1989) was unclear by analysis of the current-voltage relationship.

Although baclofen affected the current only partially, it appeared to target different channel types. This result differs from 
A
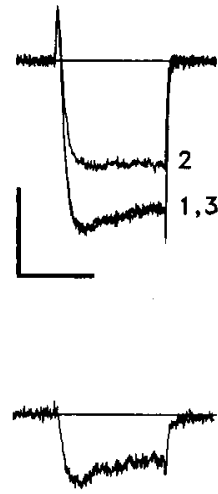

$(1-2)$

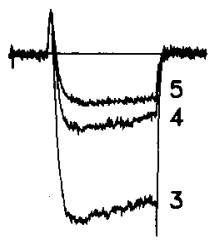

Figure 7. Combined effect of baclofen and agatx and summary of the effects. $A$, Effect of baclofen before and after application of $200 \mathrm{nM}$ agatx: representative current traces and difference traces $(+10 \mathrm{mV}$, from $-80 \mathrm{mV})$, showing the baclofen-sensitive current in control conditions and in the presence of agatx. Numbers indicate in which conditions the traces were recorded. $B$, Time course of the same experiment. $C$, Effect of baclofen on a cell pretreated with $200 \mathrm{~nm}$ agatx for $30 \mathrm{~min}$. The effect of baclofen is comparable to that of the previous cell after agatx. Calibration: $50 \mathrm{pA}, 20 \mathrm{msec} . D$, Summary of the effect of baclofen in the presence of different blockers and in different conditions. Numbers in brackets indicate the number of cells tested and error bars represent SD. *, Cells preincubated in cgtx for $30 \mathrm{~min}$; $* *$, cells preincubated in agatx for 30 $\min$.

$30 \mathrm{~min}$ agatx treat.
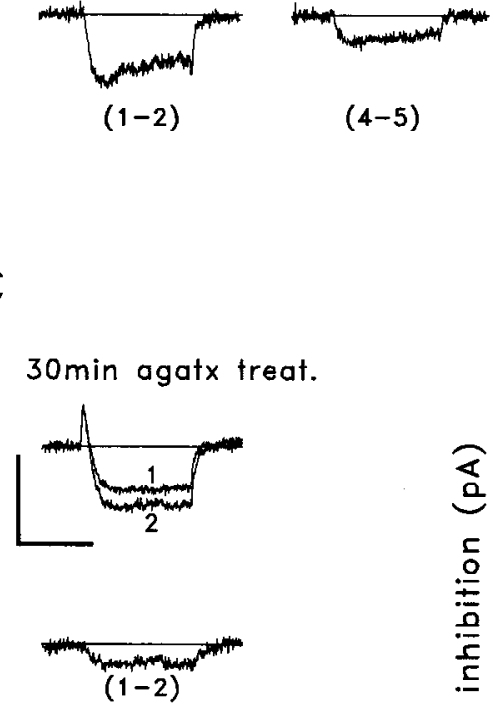

$(4-5)$
B

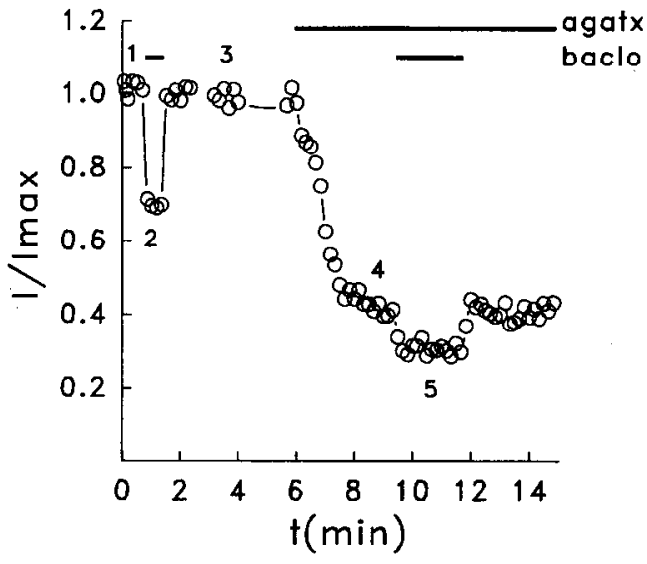

D

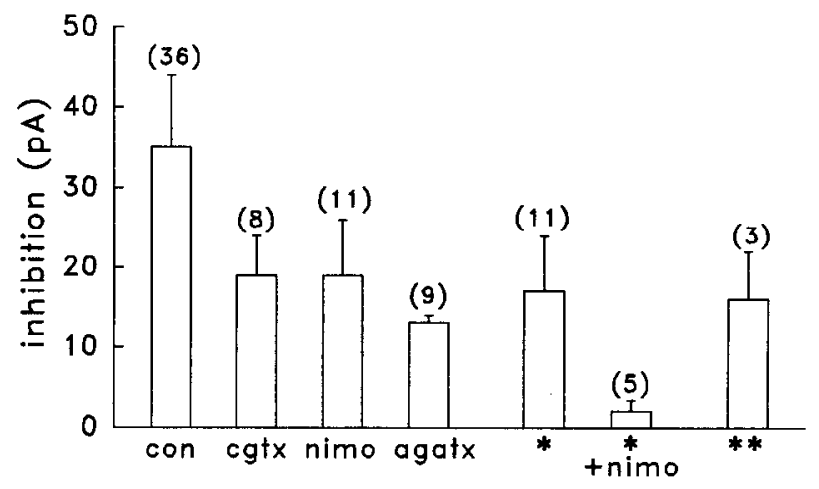

previous reports in peripheral and clonal neurons (Kasai and Aosaki, 1989; Lipscombe et al., 1989; Caulfield et al., 1992; Cox and Dunlap, 1992; Elmslie et al., 1992; Kasai, 1992; Pollo et al., 1992) and is in agreement with the work of Scholz and Miller (1991), who showed that, in pyramidal hippocampal neurons, the baclofen-induced inhibition of the calcium current was more pronounced than that caused by cgtx, and with that of Mintz and Bean (1993), who reported that baclofen modulates P-type calcium channels in central neurons.

If we interpret the action of baclofen as related to the presence of a specific modulatory site on the channel, this site should be present on cgtx-sensitive channels (as in peripheral and clonal neurons), but also in subsets of DHP- and agatx-scnsitive channels, as both nimodipine and agatx partially occluded subsequent responses to baclofen. Furthermore, the result that acute exposure to nimodipine after chronic treatment with cgtx totally prevented the action of baclofen (Fig. $6 \mathrm{D}$ ) might suggest that chronic treatment with cgtx blocks a class of channels, which includes also those targeted by both baclofen and agatx. However, this hypothesis was not tested directly in the present work.

Another observation is the distinct behavior of DHP agonist and antagonist. If baclofen affects L-channels, as unequivocally proved by the nimodipine experiments, one would expect that it would also decrease the amplitude of the BayK-induced slow tail current. However, this was not the case and this observation can have different explanations. First, one might suppose that BayK modifies the target channel, making it resistant to G-protein induced modulation. The effect of dihydropyridines has

been modelled in many different ways (Hess et al., 1984; Brown et al., 1986; Lacerda and Brown, 1989), of which a very popular one is the "modes" hypothesis (Hess et al., 1984). Following the indication of this attractive scheme, one might suppose that baclofen is not capable to modulate L-channels that are in mode 2 , the BayK-favored mode. This is possible, but in partial contrast to other two observations, which suggest instead that BayK and baclofen affect two different channel types. First, the amplitude of the current blocked by baclofen was the same before and after BayK treatment and, second, when baclofen was applied first and followed by BayK, the amplitude of the slow tail current was comparable with that induced by BayK in control. Then, we also propose the different explanation that the DHPsensitive calcium channels which are equipped with a modulatory site for baclofen-activated G-protein are not sensitive to BayK, but only to nimodipine. Any detailed description of these different L-type channels is premature and necessarily speculative, but matches with the hypothesis of different DHP binding sites, which might be differentially distributed in the subclasses of L-type channels, belonging to the $\mathrm{L}$ super fanily.

In conclusion, our results suggest that, in cerebellar granule cells, (1) cgtx-sensitive channels, which represent a minority, possess a modulatory site for baclofen-activated G-protein; (2) DHP-sensitive calcium channels are an heterogeneous population and only a subclass of these channels possesses the modulatory site; and (3) also agatx-sensitive channels are an heterogeneous population because only a subclass of these channels possesses a modulatory site for baclofen. 
A
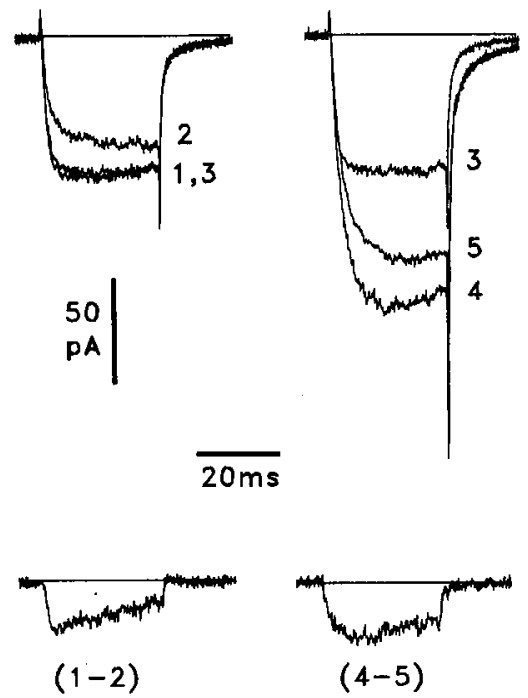

D

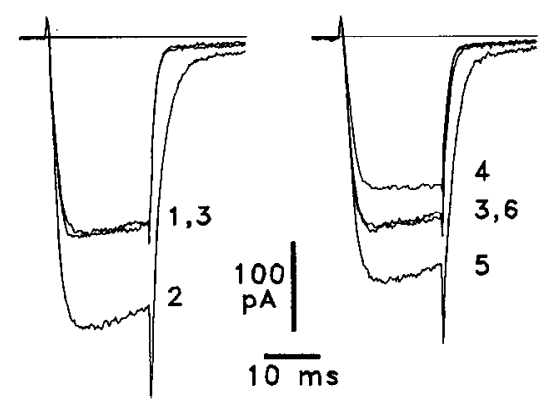

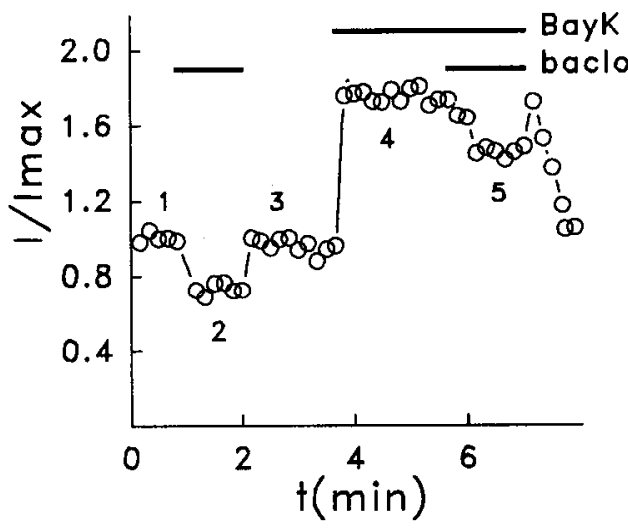

C

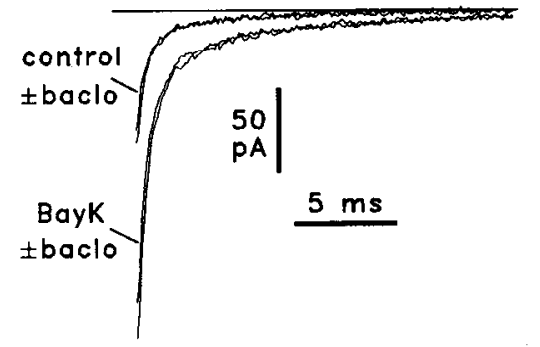

Figure 8. Combined effect of baclofen and BayK. $A$, Current traces and time course of the effect of baclofen before and after application of BayK. Difference traces (bottom) indicate that the current blocked by baclofen after BayK treatment $(r i g h t)$ is approximately the same as the current blocked by baclofen in control (left). $B$, Time course of the same experiment. $C$, Expanded plot from $A$, showing that the tail currents were not modified by baclofen. $D$, Representative current traces (left) and time course (right) of the effect of BayK before and after application of baclofen.
In view of these considerations, we suggest that a purely pharmacological classification, using the presently available specific blockers, may be inadequate to classify native central neuron calcium channels with respect to their physiological function.

\section{References}

Aosaki T, Kasai H (1989) Characterization of two kinds of high-voltage-activated $\mathrm{Ca}$-current in chick sensory neurons. Pfluegers Arch 414:150-156.

Bean BP (1989) Neurotransmitters inhibition of neuronal calcium currents by changes in channel voltage dependence. Nature 340:153156.

Brown AM, Kunze DL, Yatani A (1986) Dual effects of dihydropyridines on whole cell and unitary calcium currents in single ventricular cells of guinea-pig. J Physiol (Lond) 379:495-514.

Brown AM, Sayer RJ, Schwindt PC, Crill WE (1994) P-Type calcium channels in rat neocortical neurones. J Physiol (Lond) 475:197-205.

Caulfield MP, Robbins J, Brown DA (1992) Neurotransmitters inhibit the omega-conotoxin-sensitive component of $\mathrm{Ca}$ current in neuroblastomaglioma hybrid (NG 108-15) cells, not the nifedipine-sensitive component. Pfluegers Arch 420:486-492.
Cox DH, Dunlap K (1992) Pharmacological discrimination of N-type from L-type calcium current and its selective modulation by neurotransmitters. J Neurosci 12:906-914.

Delcour AH, Tsien RW (1993) Altered prevalence of gating modes in neurotransmitter inhibition of N-type calcium channels. Science 259: 980-984.

D'Mello SR, Galli C, Ciotti T, Calissano P (1993) Induction of apoptosis in cerebellar granule neurons by low potassium: inhibition of death by insulin-like growth factor I and cAMP. Proc Natl Acad Sci USA 90:10989-10993.

Dolphin AC, Scott RH (1987) Calcium channel currents and their inhibition by $(-)$-baclofen in rat sensory neurones: modulation by guanine nucleotides. J Physiol (Lond) 386:1-17.

Dunlap K, Fischbach GD (1981) Neurotransmitters decrease the calcium conductance activated by depolarization of embryonic chick sensory neurones. J Physiol (Lond) 317:519-535.

Ellinor PT, Zhang JF, Randall AD, Zou M, Schwarz TL, Tsien RW, Horne WA (1993) Functional expression of a rapidly inactivating neuronal calcium channel. Nature 363:455-458.

Elmslie KS, Zhou W, Jones SW (1990) LHRH and GTP- $\gamma$-S modify calcium channel activation in bullfrog sympathetic neurons. Neuron 5:75 80 . 
Elmslie KS, Kammermeier PJ, Jones SW (1992) Calcium current modulation in frog sympathetic neurones: L-current is relatively insensitive to neurotransmitters. J Physiol (Lond) 456:107-123.

Forti L, Pietrobon D (1993) Functional diversity of L-type calcium channels in rat cerebellar neurons. Neuron 10:437-450.

Fox AP, Nowycky MC, Tsien RW (1987) Kinetic and pharmacological properties distinguishing three types of calcium currents in chick sensory neurons. J Physiol (Lond) 394:149-172.

Hescheler J, Schultz G (1993) G-protein involved in the calcium channel signalling system. Curr Opin Neurobiol 3:360-367.

Hess P, Lansman JB, Tsien RW (1984) Different modes of Ca channels gating behaviour favoured by dihydropyidine $\mathrm{Ca}$ agonists and antagonists. Nature 311:538-544.

Hille B (1992) G-Protein coupled mechanisms and nervous signaling. Neuron 9:187-195.

Hilliard DR, Monje VD, Mintz IM, Bean BP, Nadasdi L, Ramachandran J, Miljanich G, Azimi-Zoonooz A, McIntosh JM, Cruz LJ, Imperial JS, Olivera BM (1992) A new conus peptide ligand for mammalian presynaptic $\mathrm{Ca}^{21}$ channels. Neuron 9:69-77.

Huston E, Scott RH, Dolphin AC(1990) A comparison of the effect of calcium channel ligands and $\mathrm{GABA}_{\mathrm{B}}$ agonists and antagonists on transmitter release and somatic calcium channel currents in cultured neurons. Neuroscience 38:721-729.

Huston E, Cullen G, Sweeney MI, Pearson H, Fazeli MS, Dolphin AC (1993) Pertussis toxin treatment increases glutamate release and dihydropyridine binding sites in cultured rat cerebellar granule neurons. Neuroscience 52:787-798

Kasai H (1992) Voltage- and time-dependent inhibition of neuronal calcium channels by a GTP-binding protein in a mammalian cell line. J Physiol (Lond) 448:189-209.

Kasai H, Aosaki T (1989) Modulation of Ca-channel current by adenosine analog mediated by a GTP-binding protein in chick sensory neurons. Pfluegers Arch 414:145-149.

Kasai H, Neher E (1992) Dihydropyridine-sensitive and $\omega$-conotoxinsensitive channels in a mammalian neuroblastoma-glioma cell line. J Physiol (Lond) 448:161-188.

Kuo CC, Bean BP (1993) G-Protein modulation of ion permeation through N-type calcium channels. Nature 365:258-262.

Lacerda AE, Brown AM (1989) Nonmodal gating of cardiac calcium channels as revealed by dihydropyridines. J Gen Physiol 93:12431273

Levi G, Aloisi F, Ciotti MT, Gallo V (1984) Autoradiographic localization and depolarization induced release of amino acids in differentiating granule cell cultures. Brain Res 290:77-86.

Lipscombe D, Kongsamut S, Tsien RW (1989) $\alpha$-Adrenergic inhibition of sympathetic neurotransmitter release mediated by modulation of N-type calcium-channel gating. Nature 340:639-642.

Llinas R, Sugimori M, Lin JW, Cherksey B (1989) Blocking ad isolation of a calcium channel from neurons in mammals and caphalopods utilizing a toxin fraction (FTX) from funnel-web spider poison. Proc Natl Acad Sci USA 86:1689-1693.

Marchetti C, Carbone E, Lux HD (1986) Effects of dopamine and noradrenaline on $\mathrm{Ca}$ channels of cultured sensory and sympathetic neurons of chick. Pfluegers Arch 406:104-111.

Marchetti C, Carignani C, Robello M (1991) Voltage-dependent calcium currents in rat cerebellar granules cells. Neuroscience 43:121133.
McCleskey EW, Fox AP, Feldman DH, Cruz LJ, Olivera BM, Tsien RW, Yoshikami D (1987) $\omega$-Conotoxin: direct and persistent blockade of specific types of calcium channels in neurons but not in muscle. Proc Natl Acad Sci USA 84:4327-4331.

Mintz IM, Bean BP (1993) GABA $A_{B}$ receptor inhibition of P-type $\mathrm{Ca}^{2+}$ channels in central neurons. Neuron 10:889-898.

Mintz IM, Adams ME, Bean BP (1992) P-Type calcium channels in rat central and peripheral neurons. Neuron 9:85-95.

Nicoll RA, Malenka RC, Kauer JA (1990) Functional comparison of neurotransmitter receptor subtypes in mammalian central nervous system. Physiol Rev 70:513-565.

Plummer MR, Logothetis DE, Hess P (1989) Elementary properties and pharmacological sensitivities of calcium channels in mammalian peripheral neurons. Neuron 2:1453-1463.

Pollo A, Lovallo M, Sher E, Carbone E (1992) Voltage-dependent noradrencrgic modulation of $\omega$-conotoxin-scnsitive $\mathrm{Ca}^{3+}$ channels in human neuroblastoma IMR32 cells. Pfluegers Arch 422:75-83.

Regan LJ, Sah DWY, Bean BP (1991) $\mathrm{Ca}^{2+}$ channels in rat central and peripheral neurons: high-threshold current resistant to dihydropyridine blockers and $\omega$-conotoxin. Neuron 6:269-280.

Sah DWY (1990) Neurotransmitter modulation of calcium current in rat spinal cord neurons. J Neurosci 10:136-141.

Sather WA, Tanabe T, Zhang JF, Mori Y, Adams ME, Tsien RW (1993) Distinctive biophysical and pharmacological properties of $A(B I)$ calcium channel al subunit. Neuron 11:291-303.

Scholz KP, Miller RJ (1991) GABA A $_{B}$ receptor-mediated inhibition of Ca currents and synaptic transmission in cultured rat hippocampal neurones. J Physiol (Lond) 444:669-686.

Snutch TP, Reiner PB (1992) $\mathrm{Ca}^{2+}$ channels: diversity of form and function. Curr Opin Neurobiol 2:247-253.

Snutch TP, Leonard JP, Gilbert MM, Lester HA, Davidson N (1990) Rat brain expresses an heterogeneous family of calcium channels. Proc Natl Acad Sci USA 87:3391-3395.

Snutch TP, Tomlinson WJ, Leonard JP, Gilbert M (1991) Distinct calcium channels are generated by alternative splicing and are differentially expressed in the mammalian CNS. Neuron 7:45-57.

Takahashi T, Momiyama A (1993) Different types of calcium channels mediate central synaptic transmission. Nature 366:156-158.

Tang S, Yatani A, Bahinski A, Mori Y, Schwartz A (1993) Molecular localization of regions in the L-type calcium channel critical for dihydropyridine action. Neuron 11:1013-1021.

Turner TH, Adams ME, Dunlap K (1992) $\mathrm{Ca}^{2+}$ channels coupled to glutamate release identified by $\omega$-aga IVA. Science 258:310-313.

Turner TH, Adams ME, Dunlap K (1993) Multiple $\mathrm{Ca}^{2+}$ channel types coexist to regulate synaptosomal neurotransmitter release. Proc Natl Acad Sci USA 90:9518-9522.

Usowicz MM, Sugimori M, Cherksey B, Llinas R (1992) P-Type calcium channels in the somata and dendrites of adult cerebellar Purkinje cells. Neuron 9:1185-1199

Wojcik WJ, Travagli RA, Costa E, Bertolino M (1990) Baclofen inhibits with high affinity an L-type like voltage-dependent calcium channel in cerebellar granule cell culture. Neuropharmacology 29: 969-972.

Zhang JF, Randall AD, Ellinor PT, Horne WA, Sather WA, Tanabe T, Schwarz. TI, Tsien RW (1993) Distinct pharmacology and kinetics of cloned neuronal $\mathrm{Ca}^{2+}$ channels and their possible counterparts in mammalian CNS neurons. Neuropharmacology 32:1075-1088. 